\title{
La oligarquía contemporánea: el gobierno de unos pocos disfrazado de democracia
}

\section{Contemporary oligarchy: the government of few disguised as democracy}

Mateo Hernández Peñaloza, Daniel Reina Serrano, Paula Rondón Mendoza

y Sara Umaña Casallas*

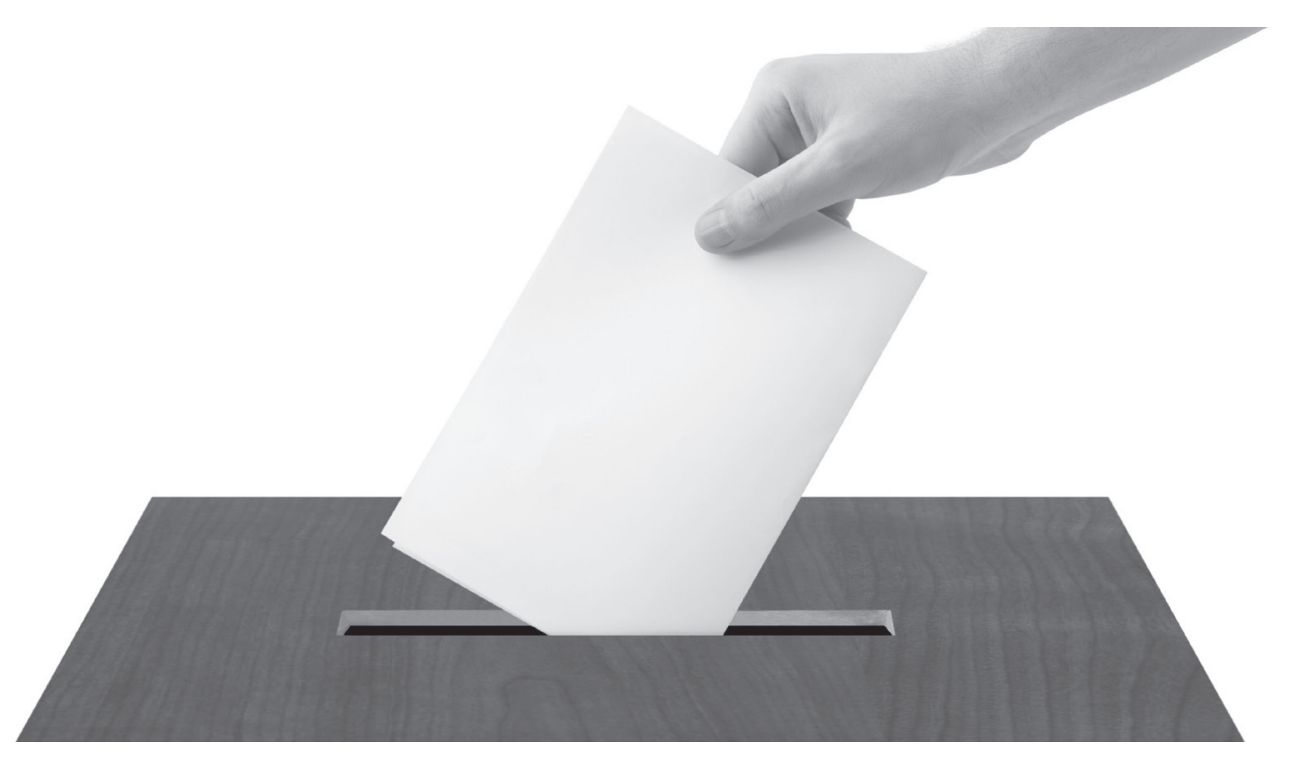

\section{Resumen}

Se nos ha vendido la idea de la democracia como el gobierno del pueblo, donde los intereses sociales son representados en una persona que la sociedad misma escoge. El presente proyecto pretende, entre muchos otros objetivos, poner en tela de juicio esta definición por medio de un análisis deductivo de las encuestas realizadas por nuestro grupo de investigación a lo largo de estos últimos meses. En Colombia, el no votar se

Citar este artículo como: Hernández Peñaloza, H., Reina Serrano, D., Rondón Mendoza, P. y Umaña Casallas, S. (2018). La oligarquía contemporánea: el gobierno de unos pocos disfrazado de democracia. Revista Papeles, 10(19), 71-82.

Fecha de recibido: 5 de marzo de 2018

Fecha de aceptacion: 20 de mayo de 2018

* Estudiantes de pregrado en Economía de la Universidad Nacional de Colombia. El presente trabajo se realizó en el marco de la asignatura Metodología de la investigación I y contó con el acompañamiento del prof. Enrique Ferrer Corredor. Correos electrónicos: Mateo Hernández Peñaloza: mhernandezpe@unal.edu.co; Daniel Reina Serrano: dreina@unal.edu.co; Pula Rondón Mendoza: prondon@unal.edu.co; Sara Umaña Casallas: sumana@ unal.edu.co 
ha convertido en un accionar general desde la mitad del siglo pasado hasta el día de hoy, y aunque la democracia no es solo votar, el ejercicio del mismo es una característica general en las sociedades democráticas y un factor categórico para conocer la voluntad de la mayoría. Nuestro fin último es que al término del trabajo el lector pueda cuestionar si el fenómeno del abstencionismo corresponde a una falta de credibilidad en la democracia, al desinterés y la desinformación de las personas, o a ambos.

Palabras clave: abstencionismo, democracia, elecciones, Colombia, gobierno, intereses sociales, información.

\begin{abstract}
It has been sold us the idea of democracy as the government of the people, where the social interests are represented by a single person elected by the society itself. The present proyect pretends, among many others objectives, put into question this definition througth a deductive analysis of the polls made by our investigation group along the last months. In Colombia the act of not voting has become a general action since the half of the last century until today, and although democracy is not just voting, this exercise is a general feature in democratic societies and a categorical factor in knowing the will of the majority. Our final purpose is that to the end of this work the reader may question if the abstentionism phenomenon corresponds to a lack of credibility in democracy, to the desinterest and desinformation of the people, or both.
\end{abstract}

Key words: abstentionism, democracy, elections, Colombia, government, social interests, information.

\title{
Introducción
}

La democracia es el modelo de organización social más extendido en el mundo, nace como una respuesta al absolutismo de la monarquía y su principal voluntad es que todos seamos representados en las decisiones de los gobiernos. Para su ejercicio, se han sugerido y puesto en marcha toda suerte de acuerdos sociales, como el respeto por la opinión ajena, que desemboca en la libertad de expresión, de pensamiento y de prensa; la libertad de catedra en las universidades, la construcción de partidos políticos con diferentes visiones de país, las garantías de una oposición, y los derechos de los ciudadanos, tales como el derecho a defender sus ideales, a la manifestación, las movilizaciones pacíficas $y$, naturalmente, el derecho a elegir y ser elegido. Para este último se estableció un mecanismo que ha ido evolucionando junto con el mismo concepto de democracia: el sufragio, en donde los ciudadanos votan a favor del candidato con el que sienten representados sus intereses. El artículo 258 de la Constitución política de Colombia sostiene que "El voto es un derecho y un deber ciudadano. El Estado velará porque se ejerza sin ningún tipo de coacción" (Const., 1991, art. 258); sin embargo, a pesar de reconocer el voto como un deber ciudadano, no estipula ningún tipo de sanción a quienes no lo ejerzan. Y entre las pocas motivaciones que se ofrecen por votar es medio día de descanso de la jornada laboral por cada jornada electoral. En el mismo artículo se establece que la primera vuelta de las elecciones puede (y debe) ser repetida 
en un único escenario: si al final del conteo, los votos en blanco constituyen la mayoría absoluta de los votos válidos. En la primera vuelta de los últimos comicios (2014) hubo un total del $6 \%$ de votos en blanco (770.610) y alrededor de 20 millones (19.758.756) de habitantes que se abstuvieron de votar. En la situación hipotética de que aquellos ciudadanos que se abstuvieron de votar hubieran manifestado su inconformismo mediante el voto en blanco, este habría sumado un poco más de veinte millones de votos (20.529.366), lo que corresponde a una cifra aproximada al $60 \%$ de la población en capacidad de sufragar. Las elecciones se habrían repetido. Este es solo un ejemplo del poder que delegan aquellos que deciden por voluntad no ejercer su derecho -y su deber- al voto.

\section{Abstencionismo en Colombia}

En búsqueda de una investigación más objetiva y clara nos hemos situado en un marco conceptual especifico que define el abstencionismo como la no participación de los ciudadanos en las actividades políticas de un país (Registraduría Nacional del Estado Civil [RNEC], Centro de Estudios en Democracia y Asuntos Electorales [CEDAE] y Universidad Sergio Arboleda, 2013). En Colombia, desde 1978 el abstencionismo ha superado el $50 \%$ en la mayoría de las ocasiones y sus causas serán el objeto de estudio de esta investigación. Las cifras recientes son alarmantes y despiertan un cuestionamiento sobre la eficacia de la democracia como mecanismo de participación. El nivel de educación, el entorno social, las creencias religiosas, el perfil socioeconómico, entre otros, son algunos de los factores que motivan a la gente a desentenderse del sufragio. El estudio realizado se basó en los resultados arrojados por unas encuestas cualitativas orientadas hacia una población específica, aquella que desde el momento en que se le concedió el derecho al voto ha decidido no ejercerlo.

\section{Historia}

Es más exacto y cómodo hablar del abstencionismo en Colombia a partir de 1978 por dos razones. La primera es que el año inmediatamente anterior se establece la Ley 27 de 1977 con la que se fija la mayoría de edad a los 18 años, la segunda es que en las elecciones de 1974 el nivel de participación fue relativamente alto (del $63 \%$, teniendo en cuenta que la mayoría de edad era 21 años), debido a que después de una época autoritaria o de democracia controlada, tal como el Frente Nacional, se celebraron las primeras elecciones libres y plurales (RNEC, CEDAE y Universidad Sergio Arboleda, 2013). La población en capacidad de sufragar de hoy en día es un poco más del doble de la de 1978 y no por eso ha aumentado el nivel de participación en las actividades democráticas del país. De hecho, el promedio de abstencionismo de las últimas diez elecciones presidenciales en Colombia ha sido de un $54.4 \%$, situándonos en el octavo lugar del escalafón de países donde el voto voluntario con mayor abstencionismo electoral en el mundo en 2015.

El nivel de abstencionismo más alto que se ha registrado en la historia del país ha sido del $66,05 \%$ en 1994, año en el que se posesiona Ernesto Samper; mas con el caso del Proceso 8000 no resulta difícil justificar la poca participación en ese momento. Por el contrario, el nivel más bajo se registró en la segunda vuelta de las elecciones siguientes con la cifra del 40,85\%, tal vez con el ánimo de no equivocarse de nuevo al dejar subir un corrupto al poder.

Los individuos no ejercen su derecho al voto porque perciben que en la relación costo beneficio, son mayores los costos de votar que los beneficios 


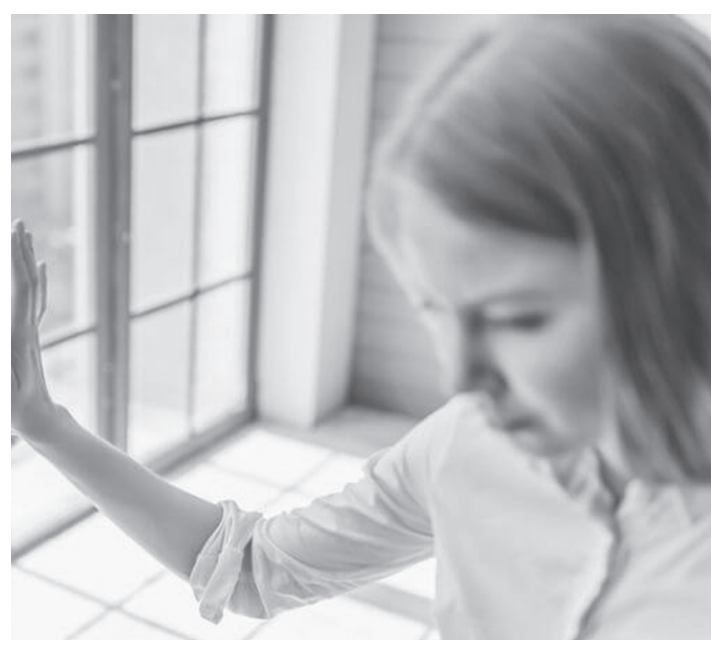

\section{Posibles causas}

Dentro del marco teórico de la elección racional planteada por Anthony Downs (1957) se establece que los individuos no ejercen su derecho al voto porque perciben que en la relación costo beneficio, son mayores los costos de votar que los beneficios. Lo anterior adquiere mayor sentido si pensamos en lo costoso que le resulta a la gente votar; por supuesto, no hablando en términos de dinero, sino en términos de tiempo: revisando y leyendo cada una de las propuestas programáticas, lo tedioso y complicado que puede llegar a ser tomar una decisión, con el agravante de que muchas veces no existe un conocimiento previo de los temas que son tratados por los candidatos en sus programas de gobierno. Es así que para muchos votantes el costo de tomar una decisión resulta mayor que el beneficio, por eso muchos delegan esta tarea de decidir a otras personas que consideran meritorias de tomar una buena decisión; mientras que muchos otros se ahorran el costo y deciden simplemente no votar.

\section{Demos-kratos}

La democracia es generalmente definida como "el gobierno del pueblo", definición que nace de su etimología griega. Sin embargo, a lo largo de la historia muchos autores han querido hacer una mayor aproximación al concepto de democracia, de manera que las definiciones abundan, incluso algunas se contradicen. En la Declaración Universal de Derechos Humanos, aprobada por la Asamblea General de la Organización de Naciones Unidas (ONU) en 1948, se proyectó claramente el concepto de democracia declarando que "la voluntad del pueblo será la base de la autoridad del gobierno" (Declaración Universal de los Derechos Humanos, 1948, art. 21). La Real Academia de la Lengua (RAE, 2018) definió democracia como "Forma de gobierno en la que el poder político es ejercido por los ciudadanos". Ambas definiciones serán incluidas dentro de nuestro marco conceptual. En virtud de esta definición, entendemos que la democracia no solo se limita al ejercicio del voto: democracia no es solo votar, tal y como dice Fernando Pinado, comisionado de democracia y participación activa en Barcelona, sino que profundiza en todas las formas en que el pueblo participa dentro de las decisiones y el control político de los gobernantes, tales como proyectos de ley, manifestaciones pacíficas, garantías de libertad de expresión; extendiendo la idea a que la democracia es un modelo político que, en teoría, debe incluir a todo los sectores de la población, donde los que ejercen el poder y son elegidos por mayorías legítimas representen la ley y a todos (Pinado, 2008).

\section{Censo electoral en Colombia}

Para tener un mayor acercamiento sobre si la democracia es el gobierno de unos pocos disfrazado del gobierno de muchos, debemos en primera medida determinar quienes son esos pocos o esos muchos; en últimas, preguntarnos: ¿qiénes votan? O aun más pertinente: ¿quiénes pueden votar? En Colombia el censo electoral lo conforman los ciudadanos Colombianos mayores de edad, exceptuando: 1) ciudadanos en servicio activo de la fuerza pública, 2) ciudadanos inhabilitados para el ejercicio de derechos y funciones públicas en 
razón de una sanción disciplinaria en firme o en sentencia penal ejecutoria y, 3) ciudadanos que no tengan registrada su cédula de ciudadanía (Congreso de Colombia, Ley 1475, 2011). A pesar de que el censo electoral se actualiza todos los días teniendo en cuenta las defunciones diarias y los nuevos ciudadanos mayores de edad nuevos este oscila entre los treinta y seis millones de habitantes (36.227.267 Actualizado el 26/05/2018). Esto es aproximadamente el $72 \%$ de la población total colombiana. Si solamente el $46,5 \%$ de la población votara, en definitiva solo $33,5 \%$ de la población estaría manifestado su voto, es decir que cualquier persona puede resultar electa solo con el voto del 16,7 \% de la población (aproximadamente ocho millones de personas).

\section{La democracia es la forma} de legitimar los poderes políticos más extendida en el mundo y es por esto que se hace importante estudiar el ejercicio de la misma desde un fenómeno que se ha venido presentando a la hora de tomar decisiones políticas

\section{Objetivos}

La democracia es la forma de legitimar los poderes políticos más extendida en el mundo y es por esto que se hace importante estudiar el ejercicio de la misma desde un fenómeno que se ha venido presentando a la hora de tomar decisiones políticas (principalmente el abstencionismo). En definitiva, nuestro objetivo más amplio es ese mismo: estudiar la democracia desde el abstencionismo; evaluando si este fenómeno, tan generalizado en Colombia, responde a una falta de credibilidad en la democracia a una falta de interés o información.

\section{Objetivos específicos}

1. Estudiar la relación entre el nivel educativo de los electores y el abstencionismo.

2. Estudiar las razones y motivaciones que mueven a las personas a no sufragar cuando poseen el derecho.

3. Evaluar si la democracia es un modelo aún vigente, en el que aun reside la confianza de los electores.

4. Examinar el silencio de los electores de manera que sea posible evaluar cuál sería un posible resultado si el abstencionismo fuera equivalente al $0 \%$.

\section{Metodología}

En virtud de realizar una investigación objetiva se diseñó una encuesta que tenía como objetivo estudiar la relación entre el perfil socioeconómico de los individuos y el fenómeno del abstencionismo, las principales razones por las que los ciudadanos deciden voluntariamente no votar, la credibilidad de la democracia como gobierno de muchos, el silencio de los votantes y los posibles escenarios si el total de la población disponible para votar lo hiciera en su totalidad. Para ello dividimos las preguntas de la encuesta formulario de tal manera que cada una correspondiera a los objetivos de la investigación.

1. Determinar el perfil socioeconómico: se compone de las primeras tres preguntas de la encuesta, las cuales están orientadas a conocer la edad, el lugar de residencia y el grado de escolaridad que la persona posee. De esta manera responde al primer objetivo.

2. Razones del abstencionismo: comprende la cuarta y quinta pregunta de nuestro 
estudio, cuya finalidad es establecer las motivaciones para que la gente no ejerza su derecho a sufragar y concretar si estas razones están fundamentadas en una falta de credibilidad en el sistema democrático, o si sirven a un simple desinterés; el segundo objetivo de la investigación.

3. La democracia en tela de juicio: abarca las preguntas seis y siete del cuestionario, y responde al tercer objetivo planteado.

4. ¿Cuál sería el resultado final si la abstención fuera de un 0 \%?: corresponde a las dos últimas preguntas de la encuesta, ocho y nueve, que pretenden revelar un posible resultado final en caso de que los encuestados se decidieran a votar (objetivo número cuatro). Por este motivo, se les preguntó su intención de voto y si lo ejercerían; fundamentados en que el panorama electoral de este periodo en específico presentó particularidades con respecto a los inmediatamente anteriores, entre otras cosas, porque ante las tensiones electorales, la participación de electores aumentó.

\section{Análisis poblacional}

Nuestra población a estudiar está conformada por las personas mayores de 25 años que no votan, preferiblemente que nunca en su vida lo hayan hecho. Estas dos características en particular son exigentes y dificultaron un poco el acceso a la información, pero resultaron sumamente fructíferas porque proporcionaron datos complementarios bastante interesantes. No es lo mismo preguntarle a un joven entre los 18 y 22 años sus razones por las cuales no va a votar, sabiendo que esta es la primera vez que puede hacerlo, que preguntarle a una persona adulta mayor de 25 años las razones de su no participación, quien ya ha tomado la decisión, por lo menos en una ocasión, de no hacerlo.
Así mismo, encontrar personas que nunca en su vida hayan ejercido este derecho y que lo vayan a hacer en esta oportunidad nos lleva a deducir que están sucediendo cosas distintas en el país durante este período de elecciones presidenciales y que, a diferencia de elecciones pasadas, el resultado permanecerá incierto hasta el conteo final. El rango de edad se mantuvo entre los 25 y los 70 años, el máximo nivel de educación alcanzado por la mayoría de los encuestados fue la básica secundaria; en cuanto a distribución poblacional, lideraron las localidades de Engativá, Kennedy y Fontibón. En las primeras dos priman los estratos 2 y 3 y en la última se suma el estrato 4.

Tabla 1. Ficha técnica de la encuesta

\begin{tabular}{|c|c|}
\hline Realizada por & Hernández, Mateo; Reina, Daniel; Rondón, Paula; Umaña, Sara. \\
\hline Universo & $\begin{array}{l}\text { Individuos mayores de } 25 \text { años colombianos que nunca hayan ejercido el } \\
\text { derecho al voto. }\end{array}$ \\
\hline Unidad de muestreo & Personas abstencionistas. \\
\hline Fecha & Entre el jueves 5 de abril y el martes 22 de mayo \\
\hline Área de cobertura & Bogotá D. C. \\
\hline Tipo de muestreo & Encuestas de carácter cualitativo y cuantitativo. \\
\hline Tamaño de la muestra & Número de personas encuestadas: 100. Número de personas anuladas: 4 . \\
\hline Objetivo de la encuesta & $\begin{array}{l}\text { Estudiar el fenómeno del abstencionismo, observando si corresponde a una } \\
\text { falta de credibilidad en el sistema democrático o a la indiferencia de los } \\
\text { individuos. }\end{array}$ \\
\hline 0 de & 9 \\
\hline
\end{tabular}

Fuente: elaboración propia 


\section{Resultados}

\section{Nivel educativo de los encuestados}

En aras de establecer una relación entre el nivel de escolaridad y el abstencionismo dividimos nuestra población entre los grados de escolaridad alcanzados por los encuestados entre básica primaria, básica secundaria, técnico o tecnólogo, pregrado profesional y posgrado; haciendo hincapié en las personas de básica secundaria (37\%), dado que es más común que las personas que alcanzan este nivel de escolaridad no voten (ver figura 1).

\section{Localidades}

Los porcentajes más altos corresponden a Engativá con un $20.2 \%$, le siguen Fontibón y Kennedy con un 9.5 \% y luego Suba con un 8.7 $\%$. Dicho esto, debemos tener presente que la mayoría de los encuestados pertenecen al estrato 3 (ver figura 2).

\section{Razones para no votar}

Dentro de las razones de los no votantes encontramos que alrededor del $48 \%$ de los encuestados convergen en que ninguno de los candidatos representa - ni ha representado- sus intereses y consideran que esta es su mayor motivación para no votar. Esto expone
Figura 1. Nivel educativo de los encuestados

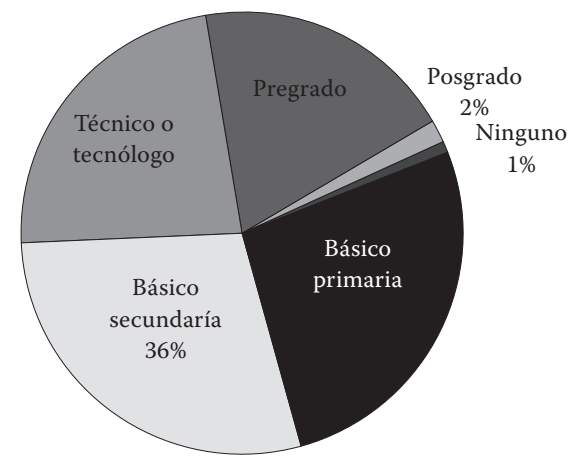

Fuente: propia

la democracia como una alternativa que representa ineficazmente al pueblo. En definitiva, el $74 \%$ de los encuestados creen que es una razón suficiente, el 16 \% una razón irrelevante y el $10 \%$ como una razón neutral. Otro de los grandes motivantes se refiere a la efectividad del voto marginal. $37 \%$ de los encuestados respondieron que no creían que su voto afectara el resultado final y que esto constituía una razón muy importante para no ejercerlo. $45 \%$ lo consideraba una razón suficiente.

Sorpresivamente, entre las tres motivaciones de los abstencionistas se encuentra una variable que depende intrínsecamente del deber ciudadano: la gente desconoce las propuestas de los

Figura 2. Localidades

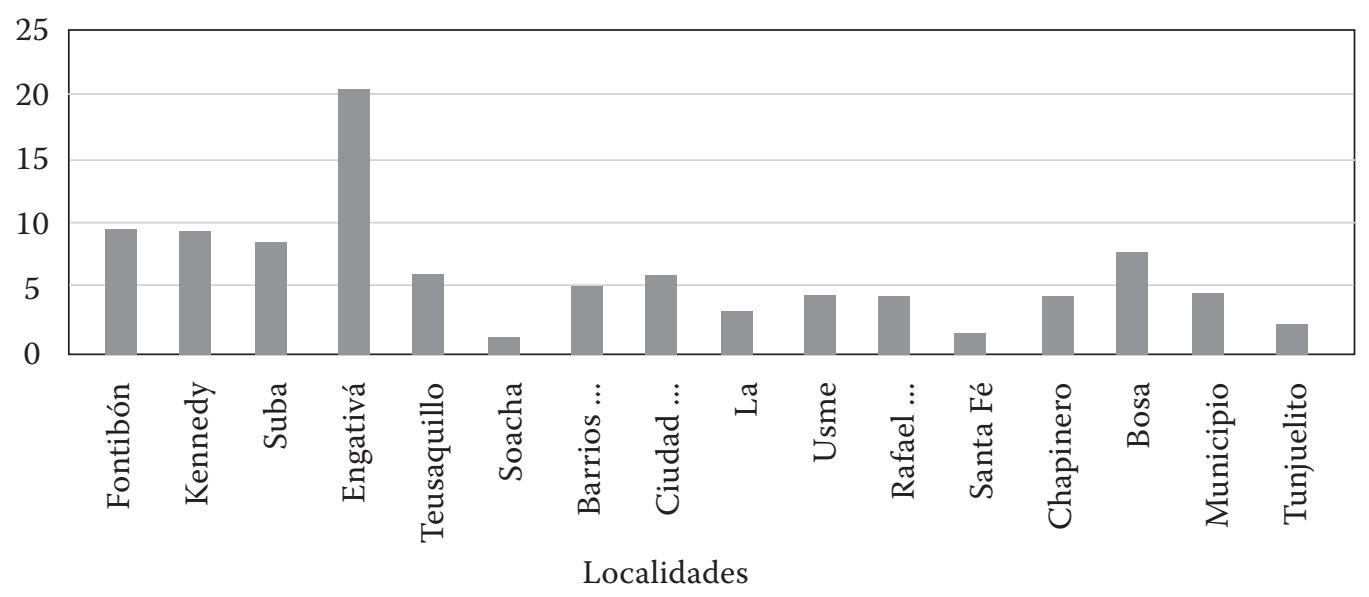

Fuente: propia 
Figura 3. Motivaciones para no votar

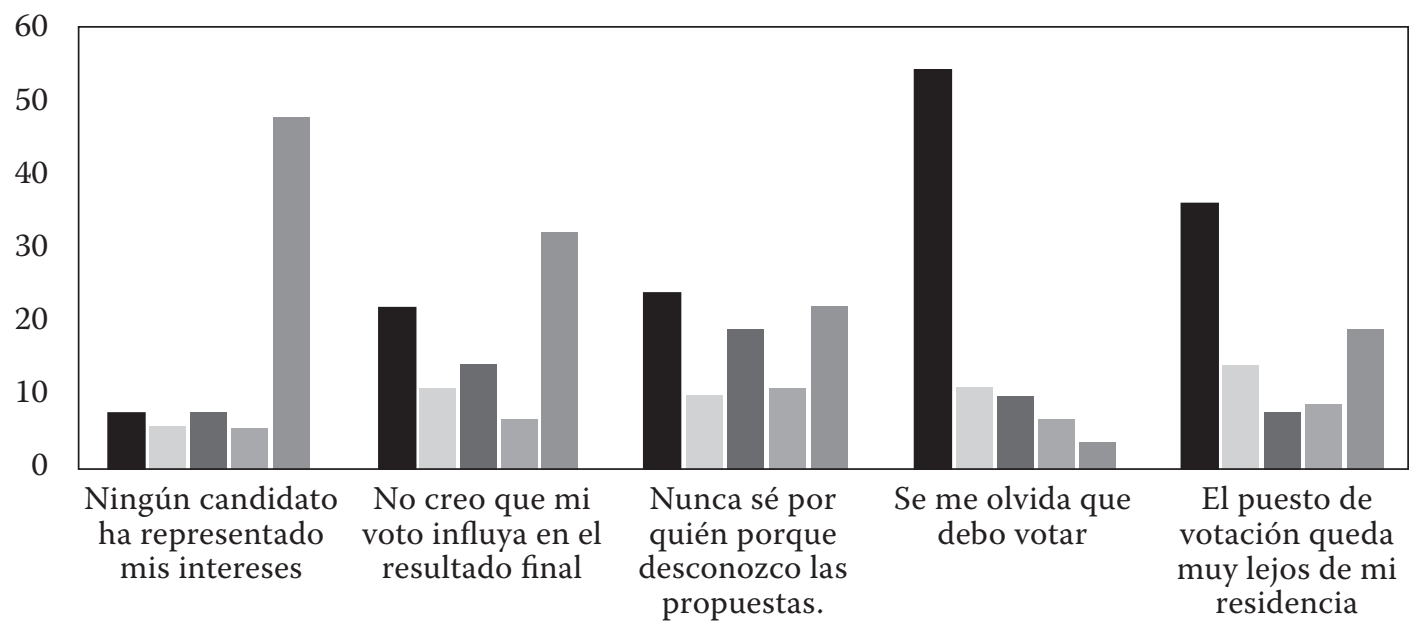

$\begin{array}{lll}\text { Serie } 1 & \text { Serie } 2 \square \text { Serie } 3 \square \text { Serie } 4 \square \text { Serie } 5\end{array}$

Fuente: propia

candidatos. $25 \%$ afirman que esta es una razón muy importante y 38 \% una razón suficiente.

Otra razón que sorpresivamente influye mucho en la decisión de votar es la distancia del puesto de votación, una variable que es completamente exógena al discurso tradicional de la democracia. 22 \% la consideran como la razón que más lo motivan a no ejercer su derecho.

Finalmente, solo el 12\% considera que no vota por que se le olvida como justificación suficiente, mientras que el $62 \%$ admite que no se le olvida votar y que esto no es una razón por la cual se abstienen, sino que lo hacen de manera consiente y voluntaria (ver figura 3 ).

Como desarrollaremos más adelante, en últimas, las motivaciones del abstencionismo suponen una elección racional de los individuos, dado que encuentran los costos mayores a los beneficios; sin embargo, al realizar un análisis más juicioso de las respuestas individuales, no todas resultan del todo coherentes. Una persona que dice que no se identifica con ningún candidato pero que desconoce las propuestas demuestra no tener argumentos válidos para abstenerse de votar.

\section{¿Los últimos presidentes han representado los intereses del pueblo?}

Consecuentemente con los resultados de la figura 1, en la figura 2 podemos evidenciar que de manera determinante las personas no se han visto representadas con los candidatos que han resultado electos, El 90\% de los encuestados respondió negativamente ante la pregunta sobre si se habían sentido representados o no por los últimos presidentes. Esto naturalmente no coincide con la definición de democracia en la que la voluntad del pueblo es la base de la autoridad del gobierno (ver figura 4).

Figura 4. ¿Sus intereses se han visto representados en los últimos gobiernos?

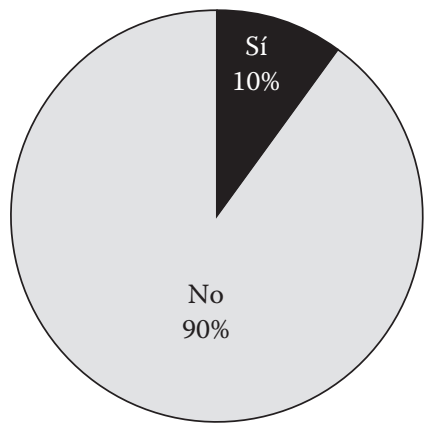

Fuente: propia 


\section{¿La democracia es un mecanismo eficaz?}

Muy a pesar de las fallas evidentes del sistema democrático, paradójicamente, la mayoría de los abstencionistas lo considera como un método eficaz a la hora de representar el gobierno del pueblo. Esto solo nos dice algo: la credibilidad en la democracia aún es favorable, aunque no por mucho, ya que la distancia entre ambos porcentajes es tan solo de 12 puntos porcentuales (ver figura 5).

Figura 5. ¿Es la democracia un mecanismo eficaz para representar la voluntad del pueblo?

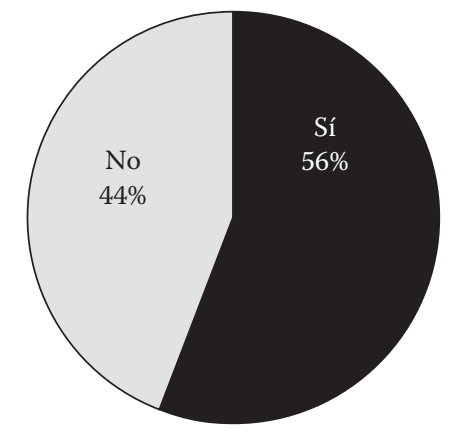

Fuente: propia

\section{¿Por quién votarían si decidieran hacerlo?}

Finalmente, para poder vislumbrar un posible resultado teniendo en cuenta el voto de aquellos que no votan, preguntamos a los abstencionistas por quién votarían si lo hicieran. Los resultados se muestran en la figura 6

Basándonos en las encuentas a nivel nacional más recientes, la conclusión más evidente es que no existe una correspondencia entre las mismas y los resultados obtenidos en nuestra muestra de la población que no vota. En nuestro caso el voto en blanco ganaría con el $31 \%$ mientras que en las encuestas, con un porcentaje cercano, se le da el primer puesto a Iván Duque, quien se encuentra en el cuarto puesto de nuestra encuesta. En últimas, el voto de los abstencionistas dista mucho de la percepción personal de que su voto no influye
Figura 6. Intención de voto

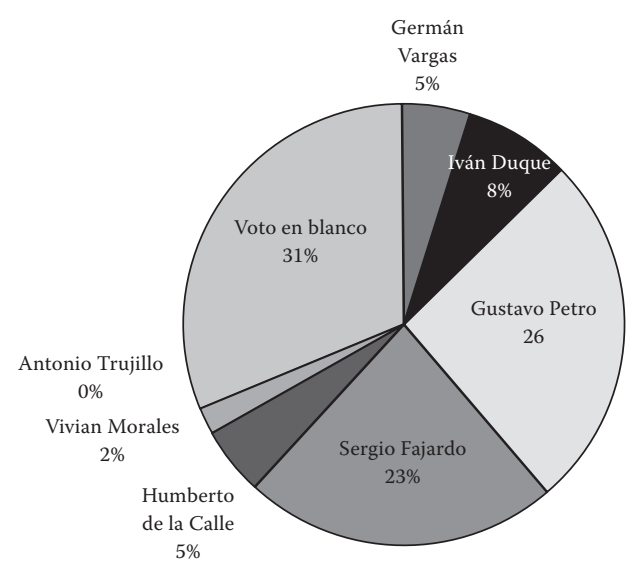

Fuente: propia

en el resultado final, porque, como vemos, cambia definitivamente el panorama electoral, ya que si ganara el voto en blanco las elecciones tendrían que repetirse, como se estipula en el artículo 258 de la constitución política de 1991.

\section{¿Votarán en las siguientes elecciones?}

En Colombia, las jornadas electorales generalmente han estado marcadas por el protagonismo de uno o dos candidatos, los que finalmente se debaten en la segunda vuelta. Estas elecciones han tenido particularidades que las hacen una jornada muy diferente a las anteriores: de los 6 candidatos, cuatro han figurado de primeros en el trajinar de las encuestas de los últimos meses (ver anexo).

Figura 7. ¿Votará en las próximas elecciones?

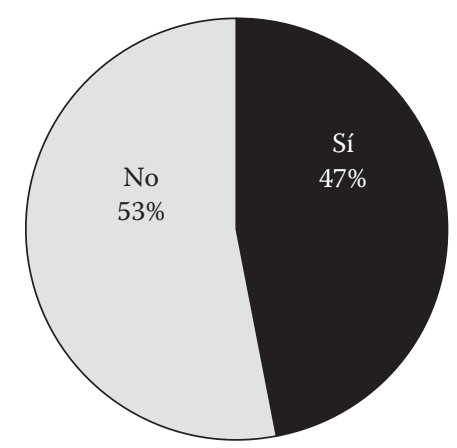

Fuente: propia 
Además, podemos agregar que son las primeras elecciones tras el acuerdo de paz con las Fuerzas Armadas Revolucionarias de Colombia. En virtud de esto, decidimos preguntarles a las personas que nunca votan, si lo harán en este momento histórico de Colombia. El resultado fue sorprendente: $47 \%$ de las personas que nunca votan se decidieron a hacerlo, y aunque no constituye la mayoría, no esperábamos que alcanzara tan alto porcentaje; pues, en definitiva, solo los separan 6 puntos porcentuales. Esto demuestra que el ambiente político está cambiando (ver figura 7).

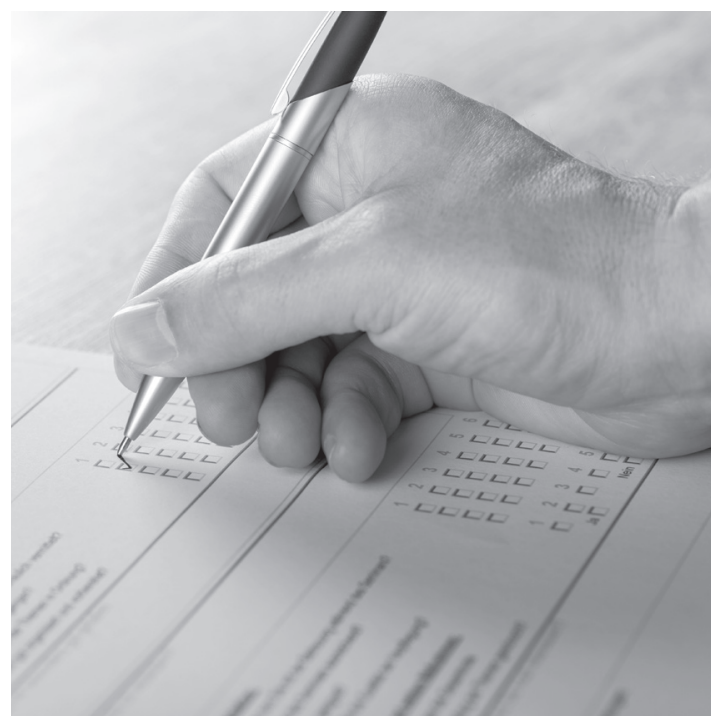

\section{Conclusiones}

Dados los resultados obtenidos podemos resumir nuestras conclusiones de la siguiente manera:

\section{El ambiente socioeconómico importa}

Hay un pequeño porcentaje de la población que no vota por motivos diferentes a los ya contemplados. A modo de dato curioso y gracias a la experiencia de realizar las encuestas nos enteramos de que los testigos de Jehová no votan por convicción religiosa; debido a su interpretación de la Biblia están convencidos de que no deben realizar ningún tipo de participación política.

Aunque resulta pernicioso decir que existe una relación intrínseca entre el nivel de escolaridad y el abstencionismo, sí podemos afirmar con certeza que el abstencionismo es mucho más elevado en personas con menores estudios: el $61 \%$ de los encuestados tiene por mucho terminada la básica secundaria.

\section{¿El voto de cada persona cuenta!}

Las personas que deciden no ejercer su voto lo hacen porque encuentran fallas en la democracia como un mecanismo que represente de manera eficiente las "voluntades del pueblo". De igual manera podemos afirmar que la gente no vota, puesto cree que su voto no afectará de manera relevante el resultado final, afirmación que resulta ser falsa, dado que si muchas personas deciden no votar motivados por ello, en suma, son muchos los votos que pueden llegar a cambiar parcial, o incluso, totalmente, el escenario electoral.

\section{La democracia pasa raspando}

La credibilidad de la democracia aún es fuerte, incluso dentro de las personas que no la practican, muy a pesar de que no sienten que sus intereses se ven representados creen que es un método efectivo para representar el gobierno del muchos.

\section{Todos votan, incluso los que no votan}

El abstencionismo de las personas es una forma de legitimar el voto de los que sí lo ejercen: todos votan, incluso aquellos que de manera voluntaria deciden no hacerlo, ya que estos están delegando su opinión a las personas que sí votan y el poder se legitima por el voto de unos pocos. Conociendo el censo electoral y descontando la población que se 
abstiene encontramos que tan solo el $16 \%$ (aproximadamente) de la población total de Colombia puede decidir el máximo cargo de la república en primera vuelta. Es decir que, vista desde el abstencionismo en Colombia, la democracia constituye el gobierno de unos pocos, una oligarquía donde un pequeño sector de la sociedad legitima el poder. No obstante, resulta necesaria hacer una distinción: es una oligarquía voluntaria, puesto que los que no votan deciden hacerlo de manera libre y voluntaria.

\section{Aún hay muchas ideologías conservadoras}

La experiencia jugó un papel sumamente importante en este trabajo. Infortunadamente, nuestra muestra no fue grande, no porque fuese difícil encontrar personas que no voten, ya sabemos que son bastantes, sino porque muchas de esas personas mantienen una ideología conservadora muy fuerte cuando se trata de política $y$, en muchas ocasiones, fueron reacias a responder la encuesta; la llenaron sin buena disposición o simplemente no la llenaron.

\section{Aún hay mucha gente que no le importa}

A pesar de que la causa que más motiva a las personas a no votar reside en los fallos de la democracia, aún hay muchagente que reconoce que no vota porque desconoce las propuestas o porque el puesto de votación le queda muy lejos. En definitiva: mera indiferencia.

\section{No votar es indiferencia, votar en blanco es inconformidad}

Tras ver los resultados de la investigación, nuestra mayor convicción es que se requiere de una mayor pedagogía en las alternativas que ofrece la ley para solventar los problemas que los abstencionistas reclaman. Un ejemplo diciente de esto es el voto en blanco, el cual, históricamente, ha obtenido un porcentaje irrisorio en los resultados finales, y que constituye un mecanismo real y eficaz para que esta falla de la representación sea contada y tenga un efecto real. Cada voto en blanco es una manifestación de que ningún candidato representa mis intereses y que por tanto requiero de nuevos. Muy por el contrario, no votar no es una manifestación de inconformidad, sino más bien de indiferencia.

\section{¿Democracia no es solo votar!}

A pesar de que en este proyecto investigativo nos hemos centrado en las prácticas de los colombianos a la hora de votar para hacer una evaluación de la democracia, aún nos hacen falta muchas aristas para lograr una valoración más exacta y diciente, como, por ejemplo, cómo se articula el diálogo, el debate y la libertad de expresión en nuestro país, factores que son categóricos en una sociedad que se dice "democrática". Esta es la punta del iceberg, una punta muy diciente que deja la discusión abierta.
Cada voto en blanco es una manifestación de que ningún candidato representa mis intereses y que por tanto requiero de nuevos. Muy por el contrario, no votar no es una manifestación de inconformidad, sino más bien de indiferencia. 


\section{Referencias}

Constitución Política de Colombia [Const.] (1991) Artículo 258. 2da Ed. Bogotá: Legis.

Congreso de Colombia. (14 de Julio de 2011) De la organización y funcionamiento de los partidos y movimientos políticos. [Ley 1475 de 2011]. DO: 48.130 .

Declaración Universal de los derechos Humanos (1948) Artículo 21. [título III].

Downs, A. (1957). An Economic Theory of Political Action in a Democracy. Journal of Political Economy, 65(2), 135-150. Recuperado de: http://www.jstor.org.ezproxy.unal. edu.co/stable/1827369

Granada, S. (2014). Elecciones presidenciales en Colombia: Las paradojas de la democracia. Iberoamericana (2001-), 14(55), 191-199. Recu- perado en: http://www.jstor.org.ezproxy.unal. edu.co/stable/24369238

Pindado, F. (2008). La participación ciudadana es la vida de las ciudades. Barcelona: Ediciones del Serbal.

RealAcademia delaLengua.(2018). Diccionario de la Real Academia de la lengua. Recuperado de: http://dle.rae.es/?id=C9NX1Wr

Registraduría Nacional del Estado Civil [RNEC], Centro de Estudios en Democracia y Asuntos Electorales [CEDAE] y Universidad Sergio Arboleda (2013). Abstencionismo electoral en Colombia: una aproximación a sus causas. Bogotá: Universidad Sergio Arboleda.

\section{Anexo 1. Evolución comparativa del favoritismo entre los candidatos a lo largo del tiempo}

\begin{tabular}{|l|c|c|c|c|}
\hline \multicolumn{1}{|c|}{ Periodo de tiempo } & Germán Vargas & Gustavo Petro & Sergio Fajardo & Iván Duque \\
\hline Mayo/17-julio/17 & $21,5 \%$ & $14,2 \%$ & $10 \%$ & - \\
\hline Agosto/17- septiembre/17 & $5,3 \%$ & $14,3 \%$ & $10,3 \%$ & $0,4 \%$ \\
\hline Septiembre/17-marzo/18 & $12,5 \%$ & $10,4 \%$ & $21 \%$ & $6,9 \%$ \\
\hline Marzo-presente & $10 \%$ & $24 \%$ & $18 \%$ & $36 \%$ \\
\hline
\end{tabular}

Fuente: tabla elaborada por nosotros con información de: el Centro Nacional de Consultoría Invamer y Datexco. 